
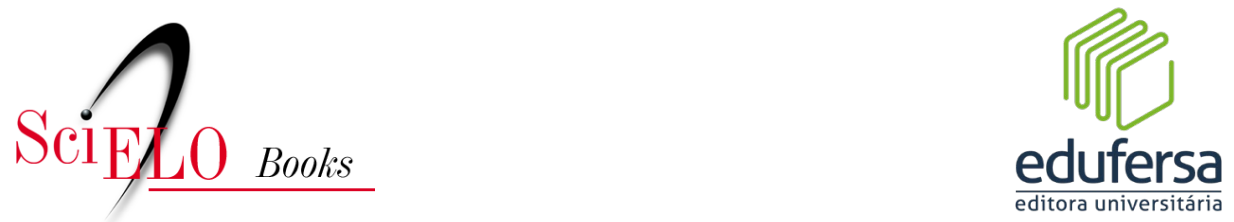

\title{
3 - Introdução à regulação do mercado de capitais
}

\author{
Luis Felipe Monteiro Seixas
}

\section{SciELO Books / SciELO Livros / SciELO Libros}

SEIXAS, L. F. M. Introdução à regulação do mercado de capitais. In: Regulação econômica no mercado de capitais e na indústria do petróleo e gás natural: assimetrias de informação, cooperação institucional e proteção do investidor [online]. Mossoró: EdUFERSA, 2021, pp. 35-62. ISBN: 978-65-87108-27-8. https://doi.org/10.7476/9786587108650.0004.

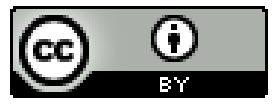

All the contents of this work, except where otherwise noted, is licensed under a Creative Commons Attribution 4.0 International license.

Todo o conteúdo deste trabalho, exceto quando houver ressalva, é publicado sob a licença Creative Commons Atribição 4.0.

Todo el contenido de esta obra, excepto donde se indique lo contrario, está bajo licencia de la licencia Creative Commons Reconocimento 4.0. 


\section{INTRODUÇÃO À REGULAÇÃ̃O DO MERCADO DE CAPITAIS}

nicialmente, cabe aqui apresentar o conceito de regulação que será adotado neste trabalho. Tendo como ponto de partida o atual modelo econômico-político de Estado regulador, a regulação compreende o conjunto de regras dirigidas a determinado mercado, funcionando como elemento harmonizador dos interesses do Estado, dos agentes econômicos e dos consumidores, com o objetivo de conciliar a livre iniciativa/livre concorrência com o interesse público. Como forma de atender seus objetivos, é conferida a competência para que determinados órgãos (agências reguladoras) criem normas voltadas para um mercado ou setor específico (petróleo, mercado de capitais, energia elétrica, telecomunicações etc.), bem como desenvolvam atividade de fiscalização e coibição/repressão de condutas reputadas ilícitas. Nas palavras de Yazbek $(2009,184)$ :

[...] a expressão regulação engloba atividades estatais que vão da criação de normas, passando pela sua implementação por meio de determinados atos administrativos e pela 
fiscalização do seu cumprimento, até a punição dos infratores. O regulador exerce um poder normativo, um poder executivo e um poder "parajudicial".

Para uma melhor compreensão da regulação do mercado de capitais, suas particularidades e propósitos, serão apresentados nos tópicos a seguir: uma introdução à teoria das falhas de mercado, seguida da discussão relacionada à teoria da regulação econômica, matriz teórica da regulação adotada no âmbito do mercado de capitais; na sequência, será dada ênfase às denominadas assimetrias de informação, a principal falha de mercado objeto de estudo neste trabalho e que possuem relevante significância no mercado de capitais; e, por último, apresentaremos os principais conceitos e finalidades relacionadas à regulação do mercado de capitais, com especial destaque à questão da proteção do investidor, assim como da coibição do insider trading.

\title{
3.1 Sobre as falhas de mercado e a teoria da regulação econômica
}

Em 1920, com a publicação da obra The Economics of Welfare (PIGOU, 1932), o economista inglês Arthur C. Pigou iniciou, a partir da discussão sobre as externalidades e os chamados impostos pigouvianos, o estudo da teoria das falhas de mercado ${ }^{3}$, principal substrato teórico a embasar, posteriormente, a teoria da regulação econômica. Nesse sentido, destaca Yazbek $(2009,34)$ :

\begin{abstract}
A análise das falhas de mercado nasce quando da publicação, em 1919, de Economics of Welfare, de Arthur Cecil Pigou. A rigor, ela é fundada sobre a constatação de que os mercados podem apresentar falhas, mostrando-se ineficientes no sentido paretiano do termo. Em uma definição clássica e largamente aceita, Bator esclarece que o tem falha
\end{abstract}

3 É atribuído à Francis M. Bator, com o artigo The Anatomy of Market Failure, a autoria do termo "falhas de mercado", conforme emprega-se atualmente. 
de mercado representa "... the failure of a more or less idealized system of price-market institutions to sustain 'desirable' or to stop 'undesirable' activities'", decorrente de determinadas distorções.

Em conjunto com os bens públicos, as falhas de competição ou concorrência, os mercados incompletos e as assimetrias de informação, as externalidades, segundo significativa parcela dos estudiosos ${ }^{4}$, configuram-se como as principais falhas de mercado que a regulação econômica busca corrigir.

A discussão anterior à teoria das falhas de mercado pode ser resumida na perspectiva do liberalismo clássico, que possuía como principal fundamento a capacidade de o mercado autorregular-se, isto é, o próprio mercado encontraria soluções para os problemas dele advindos 5 .

A partir do início do século XX, com os problemas socioeconômicos advindos após a Revolução Industrial e as crises subsequentes (em particular, a crise de 1929), percebeu-se que o paradigma da capacidade do mercado autorregular-se mostrou-se falho. Sobre o tema, assim afirma Mendes (2006, p. 110):

O abstencionismo estatal, que no âmbito econômico teve como seu grande teórico o inglês [sic] Adam Smith, gerou um grande desenvolvimento industrial e econômico, inédito

4 Por razões de caráter metodológico e de pertinência para a obra, deixamos de fora a discussão relativa à inflação e o desemprego, também considerada por alguns economistas (e por nós) como falha de mercado. Sobre o tema, cf. GIAMBIAGI, Fábio; ALÉM, Ana Cláudia. Finanças públicas - teoria e prática no Brasil. 3. ed. Rio de Janeiro, Elsevier, 2008. p. 4-8; STIGLITZ, Joseph E. Economics of public sector. 3. ed. New York: W. W. Norton \& Company, 2000. p. 77-85.

5 A metáfora que traduz a ideia de que os mercados se autorregulam, buscando uma alocação ótima dos recursos escassos, é exatamente a "mão invisível" que neles opera, metáfora esta utilizada pelo economista escocês Adam Smith, na clássica obra A Riqueza das Nações. Sobre o tema, cf. SMITH, Adam. A riqueza das nações: investigação sobre sua natureza e suas causas, vol. I. Trad. Luiz João Baraúna. São Paulo: Abril Cultural, 1983. p. 379. 
até então. Tal pensador, porém, não soube prever as potencialidades socialmente desagregadoras que tal fenômeno possuiu, mais especificamente com o surgimento de um poder econômico altamente concentrado. A "mão invisível" do mercado deparou-se com enormes conglomerados monopolísiticos e não soube e nem pôde enfrentá-los. As conseqüências sociais foram insustentáveis.

Ineficiência na produção/fornecimento de bens públicos (como saúde e educação), criação de monopólios e oligopólios (com o consequente controle de preços), e altos níveis de desemprego e inflação passaram a ser apontados como fatos que demonstravam a existência de situação onde a solução de mercado mostrava ineficiente. Advém daí a ideia de falhas de mercado, ou seja, situações onde a solução de mercado não se mostrava suficiente para resolver os problemas dele advindos.

Conforme anteriormente apontado, registrou-se cinco falhas de mercado cuja regulação econômica busca corrigir, quais sejam: os bens públicos, as falhas de concorrência ou competição, as externalidades, os mercados incompletos e as assimetrias de informação. Vejamos, separadamente, e de maneira breve, cada uma das mencionadas falhas.

Segundo a literatura econômica, os chamados bens públicos - que em nada se confundem com os bens públicos do direito civil brasileiro ${ }^{6}$ -, possuem duas características essenciais que os distinguem dos bens privados: seu uso/consumo é não-excludente e não-rival (GIAMBIABI; ALÉM, 2008, p. 4-5). Vejamos ambas as características através de um exemplo prático: a segurança pública, que no Brasil deriva de uma obrigação constitucional do Estado, é considerada um bem público conforme a teoria das falhas de mercado, exatamente porque, primeiro, o "consumo" da segurança pública por um particular não irá reduzir o consumo pelos demais indivíduos de compõe a coletividade (característica da não-rivalidade); segundo porque é virtualmente impossível impedir que um indivíduo que, por exemplo, não paga seus tributos, de se beneficiar da

6 Conforme previsto nos art. 98 a 103, do Código Civil Brasileiro. 
segurança pública fornecida pelo Estado (atributo da não-exclusão). Percebe-se, com isso, que em razão das características dos bens públicos, o mercado não possui incentivos para produzi-los (tanto porque não pode excluir indivíduos não pagantes de sua fruição, quanto porque é extremamente difícil identificar a parcela de "consumo" por cada indivíduo, e quem o consumiu), cabendo ao Estado fornecer diretamente tais bens, ou incentivar que o mercado os forneça, via regulação econômica. Outros exemplos de bens públicos são a segurança nacional, a atividade jurisdicional, o serviço de iluminação pública etc.

A segunda falha de mercado corresponde às falhas de concorrência ou de competição, traduzidas na existência de empresas monopolistas (apenas uma empresa ofertando determinado produto ou serviço) ou oligopolistas (pequeno grupo de empresas ofertando certo produto ou serviço), que detêm toda uma parcela, ou significativa parcela, de determinado segmento econômico e, com isso, dificultam ou impedem a entrada de novas empresas neste segmento, além de controlarem os preços de seus produtos e serviços, exercendo abuso de poder econômico.

No cenário modelo idealizado pelo liberalismo clássico, as empresas competem em uma concorrência perfeita, buscando ofertar os melhores produtos ou serviços aos seus consumidores; neste cenário, é natural e esperado que as melhores empresas, isto é, aquelas com os melhores produtos ou serviços (ou com menores preços) mantenham-se no mercado, enquanto as demais, caso não atinjam tais níveis de eficiência, deverão sair do mercado. Ocorre que, na prática, percebeu-se que determinadas empresas com maior poder econômico se valem de condutas de natureza anticoncorrencial (cartelização, abuso de posição dominante), visando excluir do mercado suas concorrentes e controlar o preço de seus produtos e serviços, causando prejuízo direto aos consumidores ${ }^{7}$. Em situações como essa, torna-se necessária a inter-

7 Há também o denominado "monopólio natural", que surge quando, em razão da onerosidade e complexidade para a produção de determinado bem ou prestação de certo serviço, impõe que a existência de um único produtor se mostra a mais 
venção do Estado para coibir tais falhas de concorrência, seja assumindo diretamente a posição de agente econômico (na condição de empresa estatal), de maneira monopolística, e exercendo a atividade econômica (bastante comum quando há a existência de um monopólio natural); ou seja regulando os mercados, criando normas básicas que coíbam condutas anticoncorrenciais e órgãos aptos a fiscalizar tais condutas, a exemplo do Conselho Administrativo de Defesa Econômica (CADE).

As externalidades representam situações onde os efeitos de uma determinada relação de trocas no mercado ultrapassam o espaço dos agentes diretamente envolvidos (por exemplo, comprador e vendedor), atingindo terceiros que, em princípio, não possuem qualquer correlação com a relação originária (COOTER; ULEN, 2010, p. 61). A poluição ambiental gerada por uma fábrica é o exemplo por excelência de uma externalidade negativa: de um lado, temos a fábrica, que produz determinado produto (compostos químicos, por exemplo), atendendo à demanda de seu mercado consumidor; ocorre que, em razão desta relação de troca, e da poluição ambiental gerada pela fábrica, a população que mora no entorno de seu terreno está sendo diretamente afetada, em que pese não ter não ter anuído ou sequer participar diretamente dessa relação ${ }^{8}$. Em tal cenário, o Estado pode valer-se da regulação econômica para evitar que as externalidades persistam, determinando que os agentes

viável e economicamente eficiente. Exemplos: serviços de saneamento básico e fornecimento de energia elétrica.

8 Também é possível vislumbrar a ocorrência das chamadas "externalidades positivas", que, como o termo sugere, correspondem à situações onde as relações de troca entre agentes resultam em benefícios para a coletividade, em que pese os beneficiados indiretos não terem contribuindo para tanto (um exemplo seria a aquisição, reforma e construção de uma praça por um particular em uma região então abandonada; a vizinhança irá usufruir, mesmo sem terem contribuído, de maior segurança e lazer em razão da praça construída). Neste caso, o Estado deve incentivar a ocorrência das externalidades positivas, que também poderá ocorrer através da regulação econômica (com a concessão de incentivos fiscais, por exemplo). 
econômicos "internalizem" as externalidades. Os impostos pigouvianos, mencionados anteriormente, representam a utilização da tributação para fins regulatórios, onde os agentes poluidores deveriam ter uma sobretaxa, através de um tributo específico, de maneira a compensar a coletividade pelos prejuízos advindos da poluição ambiental.

A quarta falha de mercado, os denominados mercados incompletos, representam uma dada situação onde, apesar de haver incentivos para a produção de determinado bem ou serviço (em razão de uma grande demanda por parte do mercado consumidor e os baixos custos para a sua produção), as empresas não possuem interesse em produzir tal bem ou serviço (GIAMBIAGI; ALÉM, 2008, p. 7). Essa situação (o oposto do mercado completo, onde as empresas alcançam níveis ótimos de oferta, em atendimento à demanda dos consumidores) pode ocorrer pelo fato das empresas não encontrarem um ambiente institucional propício para tanto; um mercado financeiro/de capitais pouco desenvolvido, a existência de altos custos de transação ou significativas assimetrias de informação resultam na ocorrência dos mercados incompletos, que também podem ser corrigidos através da regulação econômica.

Por último, temos as assimetrias de informação. Em um cenário ideal, em determinada relação de troca, os agentes deveriam possuir o máximo de informações possíveis sobre o produto que estão negociando: valor de mercado, qualidade, quantidade, durabilidade, todas estas são informações significativas na formação dos preços. No entanto, comumente, as partes envolvidas em uma relação de troca não dispõem de níveis ideais de informação, situação a qual, levada ao extremo, poderia impedir que a transação ocorresse, em razão da insegurança resultante do desequilíbrio informacional. A ocorrência desta falha de mercado corresponde exatamente às assimetrias de informação (COOTER; ULEN, 2010, p. 65). Um exemplo recorrente de assimetrias informacionais em uma relação de troca ocorre na compra e venda de um automóvel usado: é esperado que o vendedor, que fez uso do automóvel, conheça os potenciais defeitos existentes no veículo; por outro lado, o comprador coloca-se em uma posição de desvantagem, exatamente por desconhecer (partindo do 
pressuposto de que ele não detém conhecimento técnico para tanto) as características do automóvel. Esse mesmo exemplo é destacado por Pinheiro e Saddi (2005, p. 259):

Quando os agentes econômicos realizam trocas com base em informações incompletas sobre os custos e benefícios que cada um terá como resultado de uma transação, o mercado falha e, por conta própria, não maximiza o bem-estar social. Um caso em que isso ocorre é quando há uma assimetria de informação entre os agentes, isto é, quando uma das partes na transação sabe mais sobre o bem ou serviço transacionado do que a outra. Um caso clássico é aquele em que o vendedor sabe mais sobre o produto que comercializa do que o comprador, por exemplo, na venda de um carro usado. Só o dono sabe se, onde e como o carro sofreu algum acidente, se apresenta problemas no motor etc. O potencial comprador só vê um carro polido e lustroso, em ótimo estado.

As assimetrias de informação são bastante evidentes no mercado de capitais: de um lado temos as empresas com capital negociado em bolsa, detentoras de maiores e melhores níveis informacionais sobre suas próprias atividades e sobre o segmento econômico no qual estão inseridas; de outro, os investidores, que necessitam do máximo de informações possíveis para realizar o procedimento de tomada de decisão relativamente aos seus investimentos. Sob tal perspectiva, a proteção do investidor quanto às assimetrias informacionais existentes no mercado financeiro é condição premente para a própria eficiência do mercado. Em razão de sua importância para a obra, as assimetrias de informação serão discutidas no tópico seguinte.

Analisadas as principais falhas de mercado propostas pelos economistas, chega-se à teoria da regulação econômica em sua formulação clássica ${ }^{9}$. A regulação econômica visa exatamente corrigir ou mitigar as falhas

9 Optou-se, aqui, em analisar a teoria da regulação econômica em sua acepção 
de mercado anteriormente apresentadas. A ideia por detrás da regulação econômica é exatamente a substituição do mercado (substituição aqui compreendida como intervenção, interferência) pelo Estado, onde este último, mediante a imposição de regras cogentes ou de incentivos, irá diminuir ou corrigir práticas reconhecidas como prejudiciais para o sistema econômico. A respeito do tema, destaca Yazbek (2009, p. 34):

Neste sentido, a existência de falhas de mercado, a existência de falhas de mercado seria a primeira e principal justificativa para a intervenção estatal, destinada à sua correção ou à criação de sucedâneos para aquele mercado faltante (ainda que se possa discutir a adequação dessa criação), seja por intermédio de tributação, outorga de subsídios, regulação ou criação de infra-estrutura. Esse tipo de posição, que vê a regulação estatal como necessária para a defesa do interesse público, foi largamente adotado a partir do New Deal norte-americano.

As formas nas quais a regulação econômica é posta em prática são as mais variadas possíveis. Concessão de incentivos fiscais ou de subsídios governamentais, criação de normas de controle de comportamentos (sejam as de caráter legislativo ou administrativo/regulamentar), criação normas de incentivo ou desincentivo à prática de determinada conduta, fiscalização dos mercados, imposição de sanções etc., todas essas são práticas que podem ser adotas para fins regulatórios, com o escopo de corrigir falhas de mercado. Conforme afirma Mattos (2004, p. 50):

clássica, que imperou na literatura econômica até a década de 1960 e ainda é amplamente utilizada como parâmetro de análise. Cabe destacar que tal abordagem teórica, onde a correção das falhas de mercado ganha papel de destaque, passou a ser contestada a partir da década de 1960. Sobre o tema, cf. os artigos seminais sobre a revisão da teoria da regulação econômica elaborados por George J. Stigler (The Theory of Economic Regulation, 1971), Richard A. Posner (Theories of Economic Regulation, 1974) e Sam Peltzman (The Economic Theory of Regulation after a decade of Deregulation, 1989). 
Um desafio central para a teoria social é explicar o padrão da intervenção estatal no mercado - que podemos chamar de "regulação econômica". Quando definida de forma apropriada, a expressão se refere a todos os tipos de impostos e subsídios, bem como aos controles legislativo e administrativo explícito sobre taxas, ingressos no mercado, e outras facetas da atividade econômica.

A regulação econômica é vista, hoje, muito mais como regras de incentivo ou desincentivo, onde o Estado, mediante a criação e aplicação de normas com conteúdo jurídico ou legal, desenham um cenário de expectativa de condutas por parte dos agentes econômicos, que poderão ou não ser tomadas. Sob tal perspectiva, a criação de normas jurídicas como instrumento de regulação econômica é uma das suas principais facetas, se não a principal. Conforme destacam Pinheiro e Saddi (2005, p. 254-255):

Hoje em dia, reconhece-se que a regulação funciona de forma mais sutil, influenciando, mas dificilmente determinando com precisão o comportamento dos agentes econômicos. O desafio, então, é usar a regulação para criar incentivos para que as empresas, os consumidores e os demais agentes econômicos, ao buscar o que consideram ser o melhor para cada um de si, tomem decisões que maximizem o bem-estar social. E, como observado Ronald Coase, o "único meio de que o governo dispõe para fazer isso (aparte a exortação, que é usualmente ineficaz) é mudar a lei e a sua aplicação". A regulação consiste, portanto, do conjunto de normas, regulamentos e procedimentos, em geral oriundos do Poder Executivo, por meio das instituições responsáveis pela sua aplicação, a que o Estado recorre para alterar os incentivos e restrições com que operam os agentes econômicos, buscando corrigir as ineficiências geradas por falhas de mercado. 
Mas a regulação mediante a adoção de normas de incentivo ou desincentivo é apenas uma de suas variáveis. O Estado também pode exercer atividades de caráter fiscalizador e sancionador, com o fim de regular determinado segmento econômico. A defesa da concorrência é um exemplo onde o Estado (no caso brasileiro, através do Conselho Administrativo de Defesa Econômica ${ }^{10}$ ) é responsável por fiscalizar condutas que se configurem como abuso do poder econômico; caso tais condutas sejam confirmadas, será conferido ao órgão regulador a possibilidade de punir os agentes econômicos envolvidos.

Em verdade, o papel do Estado em regular a economia possui, no caso brasileiro, verdadeira natureza constitucional, em razão da previsão contida no artigo 174, da Constituição Federal, que confere ao Estado a função de "agente normativo e regulador da atividade econômica" (BRASIL, 1988).

Sob tal perspectiva, e conforme a construção doutrinária brasileira, a regulação econômica traduz-se na intervenção do Estado na economia, podendo ocorrer de forma direta (quando o próprio Estado exerce a atividade empresarial, seja de forma monopolística ou concorrendo com a iniciativa privada) ou indireta (através de normas de direção, de incentivos ou desincentivos). Em sua clássica obra A ordem econômica na Constituição de 1998, Eros Grau adota conceitos próprios para as formas de intervenção econômica do Estado, quais sejam, intervenção no domínio econômico (correspondente à intervenção direta) e intervenção sobre o domínio econômico (correspondente à intervenção indireta) (GRAU, 2007, p. 148).

Valendo-se da classificação de Eros Grau, temos que a intervenção no domínio econômico (ou intervenção direta) pode ocorrer tanto por absorção, quanto por participação (GRAU, 2007, p. 148). Na intervenção por absorção, o Estado assume, de maneira monopolística

10 As funções do Conselho Administrativo de Defesa Econômica estão previstas na Lei $\mathrm{n}^{\circ} 12.529$, de 30 de novembro de 2011. 
e exclusiva, xploração direta de determinada atividade econômica ${ }^{11}$.Por outro lado, na intervenção por participação, o Estado atua em regime de concorrência com o setor privado na exploração de determinada atividade econômica ${ }^{12}$.

A intervenção sobre o domínio econômico (ou intervenção indireta), por seu turno, desdobra-se em intervenção por direção e intervenção por indução (GRAU, 2007, p. 148). Na intervenção por direção, o Estado, mediante o uso de normas jurídicas de caráter compulsório, delimita o campo de atuação e decisão do agente econômico ${ }^{13}$. Já na intervenção por indução, o Estado também faz uso de normas jurídicas, buscando incentivar ou desestimular determinado comportamento por parte do agente econômico ${ }^{14}$. Neste segundo caso, em que pese a natureza de norma jurídica, as normas editadas pela autoridade estatal possuem conteúdo dispositivo, isto é, ao agente econômico é facultado cumpri-las ou não, comportamento este que poderá ser premiado ou sancionado, a depender da natureza da norma indutora, se de incentivo ou de desincentivo (GRAU, 2007, p. 150).

11 Este era o caso das atividades de exploração e produção de petróleo e gás natural, as quais, antes do advento da Emenda Constitucional $n^{\circ} 9$, de 9 de novembro de 1995, e da Lei n 9.478, de 6 de agosto de 1997, eram exercidas integralmente pela PETROBRAS, sociedade de economista mista pertencente à União Federal.

12 Complementando a nota anterior, após o advento das mencionadas normas (Emenda Constitucional n 9/1995 e Lei n 9.479/1997), houve a flexibilização do monopólio das atividades de exploração e produção de petróleo e gás, sendo conferido às empresas privadas, em regime de concorrência com a PETROBRAS, a possibilidade de exercerem tais atividades.

13 Um exemplo de norma jurídica cuja finalidade é a de intervir por direção são as normas que estabelecem o controle de preços em determinado segmento econômico (por exemplo, mercado de combustíveis).

14 Os incentivos fiscais são o exemplo por excelência de normas jurídicas de intervenção por indução. 
Sob outra perspectiva, um dos desdobramentos da teoria da regulação econômica, principalmente a partir da década de 1970, foi a política de desestatizações ocorrida nos Estados Unidos e no Reino Unido, acompanhada da criação das chamadas agências reguladoras ${ }^{15}$. No Brasil, o fenômeno foi sentido a partir do início dos anos 1990, com a denominada "Reforma do Estado", assim resumida por Mendes (2006, p. 123):

A criação de agências, porém, não ocorreu de forma aleatória. Insere-se - necessário recordar - num contexto histórico que alia alguns traços básico: crise absoluta e depauperamento do modelo de Estado interventor, prestador de serviços; início de um processo de desestatização, conferido a agentes econômicos particulares o direito de prestar serviços públicos, por meio de ato delegatório, até então prestados tão-somente por empresas estatais; necessidade de se conferir segurança e independência aos investimentos estrangeiros.

Após uma série de privatizações de empresas estatais (e da flexibilização do monopólio da exploração e produção de petróleo e gás natural, no caso do setor petrolífero), houve a criação de diversas agências reguladoras para setores econômicos específicos, a exemplo da ANATEL (Agência Nacional de Telecomunicações), da ANEEL (Agência Nacional de Energia Elétrica), e da ANP (Agência Nacional do Petróleo,

15 Em que pese sua significativa difusão na década de 1970, as agências reguladoras (ou órgãos estatais com a função de regular determinado setor econômico) não são um fenômeno recente, possuindo uma ampla tradição nos países de origem anglo-saxã, a exemplo das independent agencies americanas (com destaque para a Interstate Commerce Comission, criada em 1887), e do Board System britânico, cujo desenvolvimento remonta a segunda metade do século XIX. Sobre tema, cf. MARTÍNEZ, María, Salvador. Autoridades independientes: un análisis comparado de los Estados Unidos, el Reino Unido, Alemania, Francia y España. Barcelona: Editorial Ariel, 2002. 
hoje Agência Nacional do Petróleo, Gás Natural e Biocombustíveis), com o escopo de regular determinados mercados que eram, até então, explorados exclusivamente pelo Estado ${ }^{16}$.

Sob tal perspectiva, as agências reguladoras representam um dos instrumentos de regulação econômica à disposição do Estado, visando evitar a concentração dos mercados (via criação de monopólios), reduzir assimetrias informacionais, corrigir eventuais externalidades negativas (impondo sanções contra agentes econômicos, por exemplo). Na perspectiva brasileira, as agências reguladoras possuem como principais características: o exercício do poder normativo, editando normas de conteúdo infralegal, destinadas ao setor econômico que buscam regular; autonomias administrativa, gerencial e financeira; mandato fixo de seus dirigentes, comumente nomeados em razão de seu notório conhecimento e experiência no setor regulado; funções fiscalizatória e sancionatória, dentre outros atributos (MEDES, 2006, p. 124-131).

Apresentamos, então, duas modalidades de regulação: a exercida pelo mercado, quando inserido num ambiente de plena liberdade econômica, o que pode ocasionar na existência de falhas de mercado; e a exercida pelo Estado, que intervém na economia mediante o exercício de direto de atividade econômica, ou através da regulação via edição de normas, controle de condutas, fiscalização de mercados etc. Há, entretanto, uma terceira modalidade de regulação, de natureza intermédia, que possui importante papel para a teoria da regulação, e para o mercado de capitais em particular. Trata-se da denominada autorregulação.

A autorregulação ocorre quando os próprios agentes econômicos participantes de determinado mercado instituem regras de condutas e procedimentos de fiscalização de seu cumprimento (PINHEIRO; SADDI, 2005, p. 473). Normas criadas por conselhos de classes profissionais,

16 Cabe destacar que o Brasil também já possuía órgãos estatais com a função de regular determinados setores econômicos, a exemplo do Banco Central, do Conselho Monetário Nacional (ambos criados em 1964, através da Lei $n^{\circ}$ 4.595) e da já mencionada Comissão de Valores Mobiliários (criada pela Lei $n^{\circ}$ 6.385, de 1976). 
que vinculam seus membros (e permitem que o órgão classista puna membros que não cumpram tais normas), são um bom exemplo do exercício de autorregulação. Importa mencionar que as normas advindas da autorregulação não possuem natureza de norma jurídica, somente vinculando os agentes que decidem se submeter, voluntariamente, às normas criadas por algum órgão de natureza privada de importante relevância para determinado segmento do mercado. Nesse sentido, Yazbek (2009, p. 211) afirma:

[...] inicialmente cumpre reconhecer que ela [a autorregulação] é, de fato, regulação da atividade econômica, sendo objeto de uma imposição e não fruto de "forças equilibradas" do mercado. Trata-se, assim, de uma regulação "artificial", imposta, ainda que o seja pela própria coletividade dos agentes regulados. Evidencia-se, com isso, o segundo aspecto da auto-regulação, o fato de ela resultar de uma organização coletiva que impõe uma ordem, um conjunto de regras ou procedimentos a seus membros - ela não nasce do conjunto de operações, mas de uma estrutura que se destaca daquelas operações e dos agentes que as realizam e que, sobre eles, deverá atuar. Por fim, do até aqui exposto ressalta, também, o caráter extra-estatal da auto-regulação, que é desenvolvida por órgãos coletivos privados. Como ocorre com a regulação estatal, a auto-regulação se corporifica em mais de uma dimensão, abrangendo uma faculdade genérica de auto-regulamentação, uma faculdade de auto-execução e uma faculdade de aplicação punições, ou seja, de "autodisciplina".

No âmbito do mercado de capitais, a autorregulação ganha significativo relevo, tanto no âmbito internacional, quanto no mercado financeiro brasileiro, sobretudo após a criação do Novo Mercado. Dentre as justificativas para o exercício da autorregulação no mercado de capitais, podem ser apontadas: i) o caráter eminentemente técnico das operações realizadas em tal segmento econômico, que demandam uma regulação específica; ii) a necessidade de dinamismo e eficiência nas operações 
realizadas em bolsa; iii) a participação dos próprios agentes econômicos regulados criação das normas autorregulatórias; iv) a possibilidade de criação de padrões internacionais de autorregulação, que poderão ser adotados pelos diferentes mercados financeiros nacionais, dentre outras. Acerca da autorregulação, destacam Eizirik, Gaal, Henriques e Parente (2008, p. 197-198):

O sistema de auto-regulação vem sendo considerado, na experiência internacional, a forma mais eficaz de controle da atividade desempenhada pelas instituições intermediárias no âmbito do mercado de valores mobiliários. De fato, a doutrina reconhece que as normas internas, às quais os membros das bolsas de valores se submetem voluntariamente, muitas vezes são mais eficazes do que as normas emanadas pelo Poder Público. A maior eficácia das normas auto-reguladoras decorre do fato de elas serem elaboradas pelos próprios membros do mercado, a partir de sua experiência concreta no desenvolvimento dos negócios, tornando-as mais flexíveis e de mais fácil adequação às mudanças das circunstâncias do mercado. Ademais, a participação dos próprios regulados na disciplina de suas atividades também leva à maior eficácia da regulação, derivada da aceitação e observação menos litigiosa de sua parte. A fiscalização do mercado de capitais exclusivamente pela entidade governamental, por outro lado, tenderia a ser mais burocrática e, consequentemente, ineficiente, pois seria exercida por pessoas que não estão diretamente envolvidas nos problemas existentes na prática dos negócios.

Atualmente, no Brasil a autorregulação do mercado de capitais é exercida principalmente pela B3, através da BSM Supervisão de Mercados (BSM). 


\subsection{Assimetrias de informação no mercado de capitais}

Dentre as falhas de mercado discutidas no tópico anterior, merece destaque as denominadas assimetrias de informação, cuja influência no mercado de capitais é de significativo relevo. Conforme anteriormente mencionado, as assimetrias informacionais surgem quando, em uma determinada relação de troca entre agentes, o desequilíbrio informacional entre os agentes sobre o bem negociado (qualidade, quantidade, valor, características etc.) é de tal monta ao ponto de prejudicar a formação de preços do bem, gerando perdas de eficiência econômica. Nesse sentido, Yazbek (2009, p. 39):

Nos mercados concretos surgem situações diversas de assimetria informacional, em que tais agentes dispõem de dados distintos, tanto sob o aspecto quantitativo, quanto sob o aspecto qualitativo. Além disso, eles podem dispor, também, de fontes que lhes permitam o acesso privilegiado a informações. A consideração de tais assimetrias apresentaria uma relevância muito limitada, porém, se permanecesse limitada à criação dos mercados para informações. A sua existência pode, na verdade, trazer uma série de possíveis distorções aos mercados, não apenas por sabotar, de pronto, a presunção de plena informação que serve de pano de fundo para a análise do equilíbrio, mas também pela sua capacidade de gerar outros efeitos, mais concretos.

As perdas de eficiência em razão das assimetrias de informação vão desde a supervalorização do preço do bem (isto é, paga-se mais do que o que ele realmente vale), o aumento dos custos de transação (em razão da criação de condições para a compra dos bens, contratação de seguros etc.), podendo, inclusive, criar prejuízos ao ponto de inviabilizar a própria relação de troca à qual a assimetria de informação está vinculada.

George Akerlof, economista americano, publicou em 1970 um dos principais trabalhos sobre as assimetrias de informação, denominado The Market for Lemons: Quality Uncertainty and the Market Mechanism 
(ARKELOF, 1970). Neste trabalho pioneiro, Akerlof apresenta os principais conceitos advindos da teoria das assimetrias de informação, analisando o mercado de carros usados nos Estados Unidos, onde é utilizada a expressão lemon ("limão") para designar tal espécie de automóvel. Em tal mercado, é esperado que o vendedor de um automóvel possua maiores e melhores níveis informações do que o comprador. As informações que o vendedor possui sobre o carro serão usadas em seu favor, seja omitindo as informações negativas, ou supervalorizando informações de menor relevância. O próprio comprador, por outro lado, já inicia a negociação pressupondo que o automóvel que pretende adquirir vale menos do que o que o vendedor está pedido por ele, mesmo que, na prática, isso não seja verdade, isto é, que o automóvel possua as condições ideais que o vendedor afirma que ele possui. Tais circunstâncias irão repercutir na formação ideal de preços do automóvel, gerando perdas de eficiência econômica (AKERLOF, 1970, p. 489). Em seu trabalho, Akerlof conclui que os modelos econômicos anteriores, onde a confiança e a informação perfeita eram condições inerentes às práticas do mercado, não mais se aplicam. Por outro lado - em razão dos desequilíbrios informacionais já mencionados -, garantias informais, mesmo que não escritas, sempre serão condições necessárias para a realização de trocas no mercado (AKERLOF, 1970, p. 500).

A partir das problemáticas em torno das assimetrias informacionais, derivam três outros pontos de discussão, quais sejam, o moral hazard ("risco moral"), a seleção adversa e sinalização. Para tanto, torna-se necessário apresentar, primeiramente, a denominada "relação principal-agent".

Em determinadas relações econômicas, a exemplo da relação de emprego ou da relação entre acionistas e administradores de companhias, é possível observar a chamada "relação principal-agent". De um lado temos o principal, que pode ser exemplificado na figura do empregador ou dos acionistas de uma companhia, que contrata o agent (que, no nosso exemplo, poderá ser um empregado ou um administrador de determinada sociedade anônima). A ciência econômica aponta que o agent, assim como o principal, é um indivíduo racional e maximizador. 
Dessa forma, em que pese a sua contratação ocorrer no interesse da empresa e, por conseguinte, do principal, poderão advir situações onde o agent agirá em seu próprio benefício (YAZBEK, 2009, p. 39-40). No âmbito do mercado de capitais, em especial, o agent, muitas vezes, detém informações privilegiadas - exatamente em razão dos desequilíbrios informacionais existentes entre o principal e o agent - situação na qual ele poderá utilizar tais informações em seu próprio interesse, adquirindo ou vendendo ações da companhia em razão de determina informação relevante que possua.

A partir do conceito de principal-agent, advém a discussão relacionada ao moral hazard, em português conhecido como risco moral. Consideremos o desequilíbrio informacional existente na relação entre seguradora (neste caso, o principal) e segurado (o agent). Comumente, a seguradora (num seguro de veículos, por exemplo) busca saber o máximo de informações possíveis sobre o segurado. No entanto, a partir da contratação, a seguradora passará apenas a monitorar a conduta do segurado, sendo reduzida sua capacidade de interferência. O seguro, por um lado, após a contratação do seguro, poderá reduzir os cuidados que normalmente teria em razão da cobertura que possui. Por outro lado, o segurado também poderá omitir informações da seguradora no momento da contratação, como forma de reduzir os custos do seguro. Situações como esta, onde há uma dificuldade do principal acompanhar as ações do agent, correspondem exatamente à hipótese de moral hazard (YAZBEK, 2009, p. 40-41).

A seleção adversa pode ser ilustrada através do exemplo do mercado de carros usados empregado por George Akerlof, em trabalho anteriormente citado. Em tal mercado, deparamo-nos com situações onde é esperado que o vendedor, por conhecer as condições do automóvel que pretende vender, beneficie-se da assimetria informacional, omitindo informações relevantes que influenciariam na formação do preço do automóvel. O comprador, por seu turno, pressupondo tal cenário, tenderá a oferecer um preço inferior àquele proposto pelo vendedor (mesmo que, numa situação ideal, o automóvel valha o preço que o vendedor ofertou), 
ou até mesmo deixe de comprar o automóvel. Por outro lado, proprietários de carros usados em bom estado, antevendo situações como esta, poderão deixar de oferecer seus carros à venda, reduzindo a oferta de carros usados no mercado, que será composto apenas por veículos de qualidade inferior (YAZBEK, 2009, p. 41).

A sinalização, por fim, corresponde à situações onde, em vez de haver a retenção de informações, o agente econômico (neste caso, o agent), de forma deliberada ou não, divulga o máximo de informações possível para o principal. Em tal hipótese, o agente econômico "sinaliza" ao mercado que a qualidade de seu "produto" (YAZBEK, 2009, p. 42) é superior. No exemplo do mercado de automóveis usados, um vendedor que possua um carro usado em bom estado poderá "sinalizar" para o mercado tal informação ofertando garantias contratuais ao comprador. No mercado de trabalho, o empregado que pretende preencher determinada vaga, "sinalizará" ao empregador que possui condições de assumi-la através de um bom currículo, por exemplo. O problema surge quando há uma ampla divulgação de informações por parte do agent de forma não intencional, resultando em distorções no mercado, posto que outros indivíduos poderão se beneficiar de tais informações indevidamente.

Resta claro a influência das assimetrias de informação no mercado de capitais. Conforme já mencionado na introdução deste trabalho, a informação é um elemento-chave (se não o mais importante elemento) no mercado de capitais. É através dela que as companhias e os investidores tomam suas decisões de onde, como, quanto e quando investir. O sistema de formação de preços de uma ação está diretamente vinculado às informações que a firma presta ao mercado. Empresas "quebram" ou podem sofrer significativos prejuízos financeiros em razão de informações que não sejam fidedignas, ou que sejam divulgadas de forma equivocada. Sob tal perspectiva, é emblemático o exemplo da empresa Eron (GIRÃO, 2012, p. 27):

Um dos maiores impactos da assimetria informacional aliado às fraudes e manipulação de números contábeis foi o caso da empresa norte-americana Enron. Em 31 de dezembro de 
2000, a companhia tinha suas ações cotadas à US\$ 83,13e o seu valor de mercado era superior a 60 bilhões de dólares, o que era 70 vezes o valor do lucro e 6 vezes o valor contábil da firma. Uma empresa com todo esse valor de mercado deveria ser confiável para que as pessoas aplicassem seus recursos nela, porém em menos de um ano, a Enron perdeu quase $100 \%$ do seu valor de mercado devido ao descobrimento de irregularidades. As ações, portanto, passaram a valer US\$ 0,40 [...].

A literatura econômica sobre o tema das assimetrias informacionais no mercado de capitais discutiu, inicialmente, a denominada Hipótese dos Mercados Eficientes (HME), originalmente apresentada pelo economista Eugene Francis Fama, em seu trabalho Efficient capital markets: a review of theory and empirical work. Na perspectiva da $\mathrm{HME}$, o preço de um ativo no mercado de capitais deve ser o reflexo de todas as informações que contribuem para a formação de tal preço. Em tal cenário, parte-se do pressuposto de que as informações disponíveis no mercado para a formação dos preços dos ativos são simétricas, motivo pelo qual o preço dos ativos fornece sinais para a alocação ótima de recursos (MARTINS; PAULO, 2014, p. 35).

Na prática, conforme já apontado, é a assimetria informacional que impera. Indivíduos de posse de informações privilegiadas, que podem ou não terem sido obtidas por meios ilícitos - mas que ainda não foram divulgadas pela companhia -, poderão se beneficiar de tais informações no processo de compra e venda de ações, causando efeitos distorcivos na economia. O caso brasileiro ganha relevo devido ao fato de que há grande concentração do capital das firmas entre poucos investidores, resultando num maior desequilíbrio informacional e, por conseguinte, ganhos desproporcionais em favor daquele pequeno grupo que detém informações privilegiadas (MARTINS; PAULO, 2014, p. 35). 
As assimetrias informacionais existentes no mercado de capitais, pelos efeitos distorcivos que causam, em prejuízo às companhias e aos investidores, devem ser corrigidas, sendo a regulação um dos instrumentos por excelência para tal correção. A esse respeito, menciona Yazbek (2009, p. 42-43):

O trato com os problemas típicos da existência de assimetrias informacionais demanda, usualmente, soluções complexas. Assim, os agentes econômicos procuram proteger-se, recorrendo a soluções contratuais que reduzam a possibilidade de conduta irregular ou mesmo adotando soluções "hierarquizadas", ou seja, em alguma medida internalizadoras de certas informações. É comum também que, ante as assimetrias informacionais, os agentes econômicos sejam submetidos a mecanismos de regulação, a obrigações compulsórias de prestar informações (como ocorre em diversos dispositivos da legislação acionária, por exemplo), à necessidade de registro de certos atos (cujo conteúdo é eminentemente publicitário) etc.

Especificamente no âmbito do mercado de capitais, o princípio do full disclosure e o dever de informar, incorporados ao nosso ordenamento jurídico através da legislação societária, traduzem-se em normas de conteúdo regulatório que tem como escopo reduzir as assimetrias informacionais. A cooperação entre entres reguladores no intercâmbio de informações também se mostra útil, na medida em que permite ampliam a gama informações que as agências possuirão no âmbito de seus mercados regulados e segmentos correlatos, a exemplo do mercado de capitais e da indústria petrolífera. Tais discussões serão melhor explorada nos capítulos seguintes. 


\subsection{Regulação do mercado de capitais, proteção do investidor e insider trading}

Do ponto de vista da sua justificação, entendemos que a regulação do mercado de capitais (e também de outros setores da economia) pauta-se por dois critérios: o interesse público e os objetivos de caráter econômico. O interesse público justifica-se diante do fato de que o mercado de capitais promove o desenvolvimento econômico do país, além da necessidade de se proteger os investidores que ali operam, sendo por intermédio da regulação que se garantem tais interesses de caráter coletivo. Os objetivos econômicos estão relacionados aos interesses privados dos agentes econômicos envolvidos, onde se buscará uma regulação eficiente para que o mercado torne-se seguro, dinâmico e atrativo para investimentos, possibilitando a inserção de novas companhias e atraindo novos investidores.

Neste sentido, com relação ao interesse público, a finalidade da regulação do mercado de capitais fundamenta-se na: proteção dos investidores; eficiência do mercado; concepção e manutenção de instituições seguras e que promovam a concorrência; necessidade de se evitar a concentração e o abuso de poder econômico e de impedir a criação de situações de conflitos de interesses (EIZIRIK; GAAL; HENRIQUES; PARENTE, 2008, p. 18).

Do ponto de vista dos objetivos econômicos, a regulação do mercado de valores mobiliários possui como escopos: buscar mecanismos para tornar mais eficiente a determinação dos preços dos valores mobiliários (quanto mais rápida a reação, mais eficiente a formação dos preços e, por conseguinte, o mercado); a eficiência na alocação dos recursos, de maneira que os investidores, com base nas informações disponíveis, apliquem seu capital nas empresas com maior produtividade e rentabilidade; por fim, mitigar os custos de transação, que são aqueles observados na realização dos negócios (por exemplo: a busca de informações por parte dos investidores acerca dos ativos da empresa, suas atividades 
atuais etc.) (EIZIRIK; GAAL; HENRIQUES; PARENTE, 2008, p. 20). De maneira análoga, e com base nas lições de Nelson Eizirik, destaca Proença (2005, p. 167-168):

Neste ponto específico, a regulação do mercado de capitais deve assentar-se para: 1. Assegurar a eficácia na determinação do valor dos títulos negociados, garantido que todas as informações relevantes estarão disponíveis ao mesmo tempo para todos os investidores, de tal forma que se reflitam concretamente nos preços. 2 . Reduzir custos transacionais e aumentar a competição entre os intermediários, ao ensejo das transferências de títulos entre os participantes do mercado. 3. Manter a eqüidade nas relações dos intermediários com seus clientes, de tal modo que não haja discriminação entre os diversos tipos de clientes e a grandeza das ordens. 4. Prevenir conflitos de interesse entre intermediários e clientes, criando uma rígida separação entre as diversas atividades das instituições financeiras, como corretagem e pesquisa, administração de recursos de terceiros, underwriting, tesouraria, recursos proprietários etc. 5. Atrair a confiança do público investidor no mercado de capitais, propiciando uma relação direta entre risco e retorno, e que as informações relevantes sejam noticiadas a todos os investidores ao mesmo tempo. 6. Evitar a concentração de poder econômico, propondo um mercado pulverizado e com ampla liquidez. 7. Instituir e executar uma política fiscal que incentive o mercado, notadamente nos países onde ainda se encontre em estágio de desenvolvimento.

Relativamente à oferta de informações para os investidores, de forma a permitir uma otimização ou eficiência na formação de preços, merece destaque a regulação informacional (PINHEIRO; SADDI, 2005, p. 450), que seria aquela responsável por garantir o máximo de informações aos investidores, em quantidade e qualidade suficientes para que ele tome decisões racionais e monitore o risco de seus investimentos. 
Em que pese o ambiente de risco inerente ao mercado de capitais, a proteção dos investidores ganha relevo, sobretudo em ambientes de informações assimétricas, onde o risco do investidor ultrapassa a álea do razoável. Em tais casos, a regulação do mercado de capitais é medida premente para a redução dos riscos dos investidores, seja através de regras que obriguem às companhias a divulgar informações relevantes (em atendimento ao princípio do disclosure), seja através da criação de normas que vedem utilização de informações privilegiadas (e puna quem fizer uso delas), dentre outras. Sobre o tema, afirmam Eizirik, Gaal, Henriques e Parente (2008, p. 19-20):

A proteção dos investidores é basicamente provida mediante normas que regulam a conduta dos emissores de valores mobiliários e dos intermediários financeiros. Com relação aos emissores, as normas visam especialmente a exigir a prestação plena e acurada das informações necessárias à avaliação dos valores mobiliários ofertados e coibir os comportamentos ilegais ou abusivos dos administradores e acionistas controladores. Já com relação aos intermediários financeiros, objetivam as normas, principalmente: coibir práticas de manipulação do mercado; eliminar conflitos de interesse; impedir a discriminação entre seus clientes; e promover tratamento adequado às necessidades financeiras dos clientes.

Sob outra perspectiva, é através de informações confiáveis, divulgadas em um ambiente de transparência garantido pela regulação, que os investidores estarão aptos a tomar decisões mais racionais do ponto de vista econômico e otimizar seus investimentos. Proença afirma que (2005, p. 134):

A relevância da regulação da informação no mercado de capitais justifica-se, portanto, no sentido de ser esta um meio eficaz de proteção do investidor, já que o habilita a tomar conscientemente, ao menos, em tese, as suas decisões de investimento. 
Um dos principais problemas que a regulação do mercado de capitais deve coibir é a prática do insider trading, que corresponde à situações onde determinado agente, seja por possuir uma posição privilegiada na companhia (diretor ou administrador contratado pelos acionistas, numa típica relação de principal-agent), ou porque obteve, através de terceiros, informações privilegiadas sobre determinado fato relacionado aos negócios da companhia, faz uso de tais informações em seu próprio interesse (ou de terceiros) e contrariamente aos interesses da companhia e de seus investidores. De posse de tais informações, esse agente utiliza-as em seu próprio proveito, por exemplo, adquirindo ações da companhia (caso as informações obtidas resultem numa potencial elevação do preço das ações) ou vendendo ações (na hipótese de as informações que possuam permitam inferir que haverá uma queda no valor das ações, de maneira similar ao caso da OGX e da suposta conduta de insider trading praticada pelo empresário Eike Batista, conforme apresentado na introdução da obra). Situações como essa são típicos exemplos de insider trading.

Em outros termos, o insider trading representa situações onde um agente, detentor de informações confidenciais e que ainda não são do conhecimento do mercado, vale-se de tais informações, realizando transações em seu favor. Há, por parte do insider, o aproveitamento da informação privilegiada em seu próprio benefício, mas em prejuízo à companhia e aos demais investidores (PROENÇA, 2005, p. 41-42). Acerca do insider trading, afirma Eizirik, Gaal, Henriques e Parente (2008, p. 537):

O insider trading consiste na utilização de informações relevantes sobre valores mobiliários, por parte de pessoas que, por força de sua atividade profissional, estão "por dentro" dos negócios da emissora, para transacionar com os valores mobiliários antes que tais informações sejam de conhecimento do público. Assim agindo, o insider compra ou vende valores mobiliários a preços que ainda não estão refletindo o impacto de determinadas informações, que são de seu conhecimento exclusivo. 
Por óbvio que não será qualquer informação relevante que deve ser entendida como privilegiada, mas somente aquelas que atendam determinados requisitos ou condições, a exemplo de: possuir um razoável grau de precisão ou exatidão, restando excluídas informações baseadas em meros rumores ou suposições; dispor de caráter confidencial, ou seja, a informação ainda não foi divulgada para o público em geral; sua divulgação, caso ocorra, resultará em um efeito imediato no preço dos valores mobiliários (característica denominada como price sensitive); estar relacionada ao mercado de capitais, aos seus emissores e investidores (EIZIRIK; GAAL; HENRIQUES; PARENTE, 2008, p. 537).

$O$ insider trading representa, portanto, o resultado de assimetrias informacionais, onde o insider, em razão das informações privilegiadas que possui, atua em benefício próprio, prejudicando os demais agentes envolvidos (empresas e investidores). Em verdade, o insider trading somente é possível quando há desequilíbrio informacional; a situação contrária - um ambiente de simetria de informações, conforme o modelo apresentado pela Hipótese dos Mercados Eficientes -, práticas de insider trading seriam impossíveis de ocorrer. Sobre o tema, afirma Girão (2012, p. 32):

[...] só existe a utilização de informação privada para expropriação dos agentes que detêm menos informações porque existe assimetria informacional. Se a assimetria informacional é o fenômeno decorrente de problemas na distribuição de informações, de modo que alguns agentes do mercado têm mais informações (qualitativa e quantitativamente) que outros agentes, os dois conceitos (insider trading e assimetria informacional) estão intimamente relacionados e podem ser tratados de forma unívoca.

Por tratar-se de conduta contrária à eficiência do mercado, a regulação representa instrumento hábil para a correção do desequilíbrio informacional, minimizando ou evitando a prática do insider trading e os prejuízos dele advindos (PROENÇA, 2005, p. 136). Mediante as práticas de divulgação de informações, conforme parâmetros regulatórios previamente definidos, busca-se manter níveis ótimos de transparência das 
informações relacionadas aos fatos relevantes das companhias, ao mesmo tempo em que condiciona os agentes detentores de informações privilegiadas (potenciais insiders, portanto) a obrigação de informar ao mercado as operações que realizam (EIZIRIK; GAAL; HENRIQUES; PARENTE, 2008, p. 538) ${ }^{17}$.

Ao lado das práticas de natureza preventiva que buscam coibir o insider trading, há também normas de caráter repressivo, com o escopo de punir o agente que faz uso indevido de informação privilegiada. Nesse sentido, a legislação brasileira considera a prática do insider trading tanto um ilícito administrativo, quando um ilícito penal.

No âmbito administrativo, o insider poderá ser responsabilizado em razão da infração ao dever de lealdade, conforme previsão contida no artigo 155 da Lei das S.A. (BRASIL, 1976), cujas sanções serão impostas pela CVM. As penalidades, nos termos do artigo 11 da Lei 6.385/1976, englobam: advertência, multa, suspensão para o exercício de cargo em companhia aberta, inabilitação temporária, suspensão ou cassação da autorização ou registro para o exercício das atividades de mercado e proibição temporária para a prática de determinadas atividades. Viviane Muller Prado e Renato Vivela, na pesquisa intitulada Radiografia de insider trading na CVM, destacam que entre os anos 2002 a 2013, dentre os 677 processos administrativos sancionadores julgados em rito ordinário pela autarquia, apenas 34 processos casos envolviam casos insider trading (PRADO; VILELA, [2014?]).

Já no âmbito penal, haverá a responsabilização do insider pelo crime de uso indevido de informação privilegiada, nos termos do artigo 27-D da Lei $n^{\circ}$ 6.385/1976, com previsão de pena de reclusão, de 1 a 5 anos, e multa de até 3 (três) vezes o montante da vantagem ilícita obtida em decorrência do crime (BRASIL, 1976).

17 As normas de caráter regulatório que buscam prevenir a prática do insider trading, conforme adotadas na legislação brasileira, serão discutidas no capítulo seguinte. 